\title{
Memória e Legitimação: as tipologias monetárias dos divinos Cláudio Gótico, Constâncio Cloro e Maximiano Hercúleo (317-318)*
}

Diogo Pereira da Silva**

SILVA, D.P. Memória e Legitimação: as tipologias monetárias dos divinos Cláudio Gótico, Constâncio Cloro e Maximiano Hercúleo (317-318). Revista do Museu de Arqueologia e Etnologia, São Paulo, 18: 279-286, 2008.

Resumo: Neste artigo, temos por objetivo principal refletir sobre os usos da memória na legitimação política de Constantino I (306-337), através da análise das tipologias e legendas monetárias dos diui Cláudio Gótico (268-270), Constâncio Cloro (293-306) e Maximiano Hercúleo (286-305, 306-308) emitidas pelas Casas de Cunhagem de Aquiléia, Arles, Roma, Siscia, Tessalônica e Trier entre os anos 317 e 318.

Palavras-chave: Baixo Império Romano - Constantino I - Memória Legitimação - Numismática.

\section{Introdução}

( $)$ estudiosos têm se aproximado dos problemas da cunhagem de Constantino I (306-337) por muitos ângulos - econômico, religioso, político, entre outros. Entretanto, nesta vastidão de monografias e artigos um aspecto tem sido negligenciado, ou tratado

$\left.{ }^{*}\right)$ As reflexões presentes neste artigo fazem parte da pesquisa de mestrado que desenvolvemos no âmbito do Programa de Pós-Graduação em História Comparada da Universidade Federal do Rio de Janeiro (PPGHC/UFRJ), vinculada também ao Laboratório de História Antiga da mesma instituição (LHIA/UFRJ).

Nesta pesquisa analisamos os mecanismos de afirmação política de Constantino I (306-337), em especial as representações da figura deste imperador na documentação escrita cristã e pagã, e na documentação numismática.

$\left.{ }^{* *}\right)$ Aluno de mestrado do Programa de Pós-graduação em História Comparada da UFRJ. Membro do Laboratório de História Antiga (LHIA).diogo_hist@yahoo.com.br apenas de passagem, refiro-me ao estudo das tipologias e legendas monetárias cunhadas entre 317 e 318 e que carregam as efígies dos imperadores Cláudio Gótico (268-270), Constâncio Cloro (293-306) e Maximiano Hercúleo (286$305,306-308)$ - imperadores que se tornaram diui após as suas mortes. Neste sentido, pretendo fazer uma pequena contribuição ao estudo da numismática constantiniana ao refletir através das emissões monetárias a relação entre memória e legitimidade.

Circunscrevendo o escopo documental do presente artigo, trabalharemos com as moedas emitidas pelas Casas de Cunhagem das cidades de Aquiléia, Arles, Roma, Siscia e Tessalônica, e que, por sua vez, foram catalogadas pelo numismata finlandês Patrick Bruun para o projeto The Roman Imperial Coinage, cujo volume VII foi editado pela primeira vez em 1966.

Neste artigo não nos deteremos no estudo dos pesos, das ligas metálicas, dos aspectos peculiares de cada série - tais como 
marca das oficinas de cunhagem -, pois apontaria caminhos outros que nos afastariam da problemática proposta. Deste modo, daremos enfoque ao estudo da iconografia e das legendas monetárias, partindo do pressuposto de que a moeda é um veículo importante para a divulgação de mensagens da autoridade que a cunhou (Howgego 1995: 73; Florenzano 1985: 15).

Secionaremos este trabalho em três partes. Inicialmente (1) apresentaremos nossos pressupostos teóricos, em especial os conceitos de memória e legitimidade. Em seguida, (2) analisaremos as tipologias e legendas monetárias propostas; e, por fim, (3) estabeleceremos o papel das moedas na difusão de certa memória histórica, que tinha por objetivo legitimar o poder imperial de Constantino e de seus filhos.

\section{Memória e legitimidade}

O que é memória? Se recorremos aos léxicos latinos, veremos que este substantivo deriva do substantivo feminino latino memoria, -ae que pode ter as seguintes definições: 1) memória, lembrança, recordação; 2) monumentos comemorativos; 3) tempo passado, tradição; 4) época, tempo; 5) história, relação, anais, narração (Faria 1967: 602).

Com base nestas definições, percebemos que a memória se forma na dialética entre o passado e o presente, e na relação entre indivíduo e sociedade, uma vez que memória é lembrança, monumento, tradição, tempo, história e narração. Tendo em vista a discussão desenvolvida por Pierre Nora (1984: 30), observamos que a memória é sempre carregada por grupos vivos, e, por isso, se encontra em permanente evolução, aberta à dialética da lembrança e do esquecimento, vulnerável aos usos e manipulações, suscetível a latências e revitalizações.

Por conseguinte, o seu conteúdo encontra-se inseparável não somente das expectativas em relação ao futuro como dos seus campos de objetivação - linguagem, imagens, relíquias, lugares, escrita, monumentos - e dos ritos que o reproduzem e transmitem dentro de certo campo semântico; o que mostra também que ela nunca se desenvolverá, no interior dos sujeitos, sem suportes materiais sociais e simbólicos da memória (Catroga 2001: 23).

Por seu lado, a formação da memória individual ocorre na coexistência, nem sempre pacífica, de várias memórias (pessoais, familiares, grupais, regionais, nacionais, transnacionais, culturais etc.) em permanente construção devido à incessante transformação do presente em passado e às conseqüentes alterações ocorridas no campo das representações do passado. Significa isto que a recordação - enquanto presente-passado - é experiência interior na qual a identidade do eu unifica a complexidade dos tempos sociais em que cada vida individual coparticipa (Catroga 2001: 16).

Assim sendo, a memória se encontra no centro dos debates acerca das identidades individuais e coletivas, posto que, conforme afirma Fernando Catroga (2001: 55):

"a expressão coletiva [da memória] também atua como instrumento e objeto de poder(es), quer mediante a seleção do que se recorda, quer do que, consciente ou inconscientemente, se silencia. E quanto maior é a sua expressão social, mais se corre o risco do esquecido ser conseqüência lógica da 'invenção' ou 'fabricação' de memória(s)".

O segundo conceito que trabalhamos é o de legitimidade. Partimos das discussões do Dicionário de Política (Bobbio, Matteucci, Pasquino 2004: 675) no qual:

"Num primeiro enfoque aproximado, podemos definir legitimidade como sendo um atributo do Estado, que consiste na presença, em uma parcela significativa da população, de um grau de consenso capaz de assegurar a obediência sem a necessidade de recorrer ao uso da força, a não ser em casos esporádicos. É por esta razão que todo o poder busca alcançar o consenso, de maneira que seja reconhecido como legítimo, transformando a obediência em adesão. A crença na legitimidade é, pois, o 
elemento integrador na relação de poder que se verifica no âmbito do Estado”.

Neste sentido, há uma forte relação entre memória e legitimidade, uma vez que um dos usos principais da memória é na afirmação do poder político quer pelas recordações monumentos, comemorações, rituais, objetos -, quer pelos esquecimentos. Sendo a legitimidade um atributo do Estado - e, em nosso caso, específico da pessoa do imperador, e das pessoas próximas a ele -, observamos ambos os movimentos inerentes à memória - as recordações e os esquecimentos - como forma de promover a adesão completa, por parte dos súditos, ao sistema político.

\section{As tipologias monetárias em memória de Cláudio Gótico, Constâncio e Maximiano}

As moedas que analisamos foram cunhadas entre os anos de 317 e 318, sendo séries compostas de frações do follis - moeda de bronze que passou a ser cunhada após a Reforma Monetária de Diocleciano, ocorrida em 294.

Estas séries foram emitidas pelos principais centros de cunhagem dos domínios de Constantino no ocidente - Aquiléia, Arles, Roma e Trier - e de seus novos domínios balcânicos conquistados após a primeira Guerra Civil contra Licínio (ocorrida entre 315-316) - Siscia e Tessalônica.

O número total de moedas - catalogadas por Patrick Bruun - que compõem nosso corpus é de cinqüenta e cinco moedas com tipologias diferentes. Destas, dezoito apresentam a efígie e a legenda de Maximiano Hecúleo; dezoito foram cunhadas em honra de Constâncio, e dezenove em homenagem a Cláudio Gótico.

Nestas séries, Constantino celebrou a memória de imperadores divinizados dos quais ele e seus filhos descendiam. Estas moedas tinham por objetivo glorificar a memória destes imperadores, através das legendas e tipologias de anverso e reverso, proclamando seus grandes méritos para o bem da Res publica.

Cabe ressaltar que nas séries analisadas havia mais de um tipo de onomástica para cada um desses diui, são eles:
- Cláudio:

DIVO CLAVDIO OPTIMO IMP presente em sete tipos de moedas, cunhadas em Aquiléia (2), Trier (1), Roma (2), Siscia (1) e Tessalônica (1); cujo grau de raridade varia entre $r^{1}$ e $r^{5}{ }^{1}$

DIVO CLAVDIO OPT IMP - presente em onze tipos de moedas, cunhadas em Arles (2), Trier (1), Roma (7) e Siscia (1); cujo grau de raridade varia entre $r^{1}$ e $r^{5}$;

DIVO CLAVDIO - tipologia presente em uma série cunhada em Roma; cujo grau de raridade varia entre $r^{4}$ e $r^{5}$;

\section{- Constâncio Cloro:}

\section{DIVO CONSTANTIO OPTIMO IMP -} tipologia presente em uma série cunhada em Trier; cujo grau raridade foi estabelecido em $\mathrm{r}^{5}$;

\section{DIVO CONSTANTIO OPT IMP -} tipologia presente em duas séries cunhadas em Trier; cujo grau de raridade foi estabelecido em $\mathrm{r}^{4}$;

\section{DIVOCONSTANTIO PIO PRINCIPI -} presente em quatro tipos de moedas, cunhadas em Roma (2), Siscia (1) e Tessalônica (1); cujo grau de raridade varia entre $\mathrm{r}^{3}$ e $\mathrm{r}^{5}$;

DIVO CONSTANTIO PIO PRINC presente em sete tipos de moedas, cunhadas em Aquiléia (1), Roma (5), e Siscia (1); cujo grau de raridade varia entre $r^{2}$ e $r^{5}$.

(1) O grau de raridade varia entre $c^{3}$ e $r^{5}$, representando a quantidade de exemplares conhecidos de cada tipo de moeda, segundo o quadro (Bruun 1966: xix):

\begin{tabular}{|c|c|c|c|c|}
\hline $\mathrm{r}^{5}$ & Único exemplar & $\mathrm{s}$ & $16-21$ & “ \\
\hline$r^{4}$ & 2-3 moedas conhecidas & $c^{1}$ & 22.30 & “ \\
\hline$r^{3}$ & $4-6 \quad$ " & $c^{2}$ & $31-40$ & “ \\
\hline$r^{2}$ & $7-10$ & $c^{3}$ & $41-$ & “ \\
\hline$r^{1}$ & $11-15$ & & & \\
\hline
\end{tabular}


DIVO CONSTANTIO PIO PRIN tipologia presente em três séries cunhadas em Arles (2) e Aquiléia (cujo grau de raridade foi estabelecido em $\left.\mathrm{r}^{4}\right)$.

DIVO CONSTANTIO - tipologia presente em uma série cunhada em Roma (cujo grau de raridade varia entre $r^{4}$ e $r^{5}$ ).

- Maximiano Hercúleo:

DIVO MAXIMIANO OPTIMO IMP presente em quatro tipos de moedas, cunhadas em Roma (2), Trier (1) e Tessalônica (1); cujo grau de raridade varia entre $\mathrm{r}^{4} \mathrm{e} \mathrm{r}^{5}$.

\section{DIVO MAXIMIANO OPT IMP -} tipologia presente em uma série cunhada em Trier; cujo grau de raridade foi estabelecido em $\mathrm{r}^{4}$.

DIVO MAXIMIANO SEN FORT IMP presente em sete tipos de moedas, cunhadas em Roma (6), Siscia (1); cujo grau de raridade varia entre $r^{2}$ e $r^{3}$.

\section{DIVO MAXIMIANO SEN IMP -} presente em quatro tipos de moedas, cunhadas em Aquiléia (2), Arles (1), Siscia (1); cujo grau de raridade varia

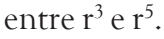

DIVO MAXIMIANO SEN - tipologia presente em uma série cunhada em Roma; cujo grau de raridade foi estabelecido em $\mathrm{r}^{4}$.

No que se refere às legendas de reverso das moedas temos dois tipos: (1) a legenda REQVIES OPTIMORVM MERITORVM - e suas variações de escrita - encontrada em trinta e seis das cinqüenta e cinco moedas de nosso corpus. Este tipo de legenda foi cunhado em todas as seis Casas de Cunhagem em estudo, e relacionado aos três imperadores, entre os anos de 317 e 318 .

Em segundo lugar, (2) temos a legenda MEMORIAE AETERNAE, presente nas dezenove moedas restantes de nosso corpus. Este tipo de legenda só foi cunhado em Roma, entre os anos de 317 e 318.

As tipologias de anverso exibidas pelas cinqüenta e cinco moedas que compõem nosso corpus possuem o mesmo tipo de efígie, na qual o imperador em questão - seja Cláudio, Constâncio ou Maximiano - aparece velado e laureado, voltado para a direita - conforme o exemplo da Moeda 1.
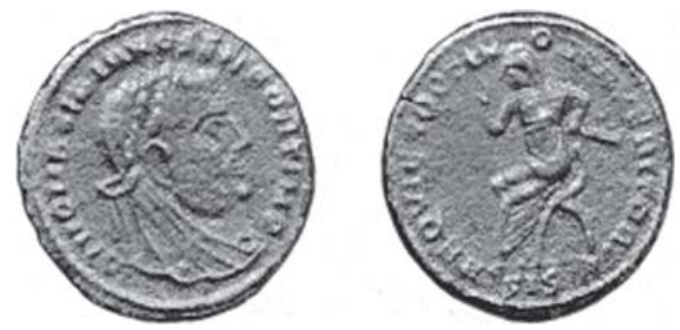

- Datação: Siscia, 318. AE / Follis

- Anverso: Imperador velado e laureado à direita - Legenda: DIVO CLAVDIO OPTIMO IMP

Desenvolvimento: Divo Cláudio Optimo Imp(eratori) Tradução: Ao divino Cláudio Ótimo Imperador - Reverso: Imperador velado sentado à esquerda, numa cadeira curul, com o braço direito levantado, segu rando um cetro com a mão esquerda.

- Exergo: SIS

- Legenda: REQVIES OPTIMORVM MERITORVM Desenvolvimento: Requies Optimorum Meritorum Tradução: Descanso pelos ótimos méritos

- Raridade: $\mathrm{r}^{3}$

- Bibliografia: RIC VII, Siscia 43

- Escala: 10:1

No que se refere às tipologias de reverso, nas séries que possuem a legenda REQVIES OPTIMORVM MERITORVM, sempre está exposta a imagem do imperador velado, sentado numa cadeira curul com o braço direito levantado e um cetro na mão esquerda.

Esta peça - Moeda 1 - apresenta um rico potencial analítico. Na legenda de anverso, temos DIVO CLAVDIO OPTIMO IMPERATORI uma legenda em dativo, o que significa que é uma dedicatória de Constantino a seu divino ancestral, a qual aparece em dezoito dos dezenove tipos de moeda dedicadas a Cláudio Gótico.

A ligação entre o Divino Cláudio Gótico e a família de Constantino aparece pela primeira vez na documentação escrita num panegírico 
pronunciado em 310 (Pan. Lat. VII 2,1) - o mesmo em que o deus Apolo aparece a Constantino -, e surge novamente na História Augusta (SHA

Diuus Claudius VIII 3), o que mostra que esta memória, possivelmente construída, foi bastante difundida a partir do reinado de Constantino.

Neste caso, OPTIMO IMPERATORI dialoga com a legenda do reverso, REQVIES OPTIMORVM MERITORVM - "descanso pelos ótimos (grandes) méritos”, legenda estampada em doze das dezenove moedas deste imperador. Cláudio é um optimus imperator por suas ações, principalmente, suas vitórias sobre os germanos na fronteira do Danúbio, e por isso, tem direito a seu merecido descanso.

Quanto à tipologia de anverso, o imperador aparece velado, o que denota que está morto, pré-requisito para se tornar um diuus; enquanto a coroa de louros se relaciona aos triunfos deste imperador.

No que se refere ao reverso, o imperador aparece como um magistrado romano (cadeira curul), com a mão direita levantada e o cetro símbolos do comando -; da mesma forma que no anverso, o imperador aparece velado. Esta tipologia se relaciona à legenda REQVIES OPTIMORVM MERITORVM uma vez que o imperador aparece numa posição de domínio sentado - com os atributos de poder.

Estas mesmas tipologias de anverso e reverso, e a mesma legenda de reverso, são encontradas em moedas do pai de Constantino - Constâncio Cloro - e de seu sogro Maximiano Hercúleo. As diferenças repousam principalmente na onomástica imperatória. Enquanto para Constâncio predominam as legendas DIVO CONSTANTIO PIO PRINCIPI - catorze de dezoito tipos -, para Maximiano temos as legendas DIVO MAXIMIANO SENIORI FORTISSIMO IMPERATORI - em doze das dezoito moedas Maximiano exibe o adjetivo senior, o qual é acompanhado do superlativo fortissimus em sete destes doze tipos.

Pelas diferentes onomásticas imperatórias percebemos as diversas formas de apropriação da memória dos imperadores falecidos. De um lado, temos Constâncio cuja pietas e o status de princeps são euforizados; de outro, temos Maximiano do qual se destaca a sua posição como Senior na hierarquia do sistema político da
Tetrarquia - uma vez que quando da abdicação de 305, tanto ele quanto Diocleciano assumiram a titulatura SENIOR IMPERATOR. Também foi destacado o poder militar, através do adjetivo no superlativo Fortissimus.

Assim sendo, dois tipos de memórias diferentes foram enfatizadas em Constâncio e Maximiano. De um lado temos o imperador "piedoso" e um exemplo de princeps, de outro temos o imperador militar, e legítimo titular do sistema político organizado por Diocleciano a partir de 286.

Referente à outra legenda de reverso MEMORIAE AETERNAE -, temos duas tipologias distintas de reverso, na primeira reproduzida na Moeda 2 - temos um leão que avança da esquerda para a direita; num segundo tipo - Moeda 3 -, apresenta-se uma águia com as asas estendidas, voltada para a esquerda, e com a cabeça voltada para a direita.

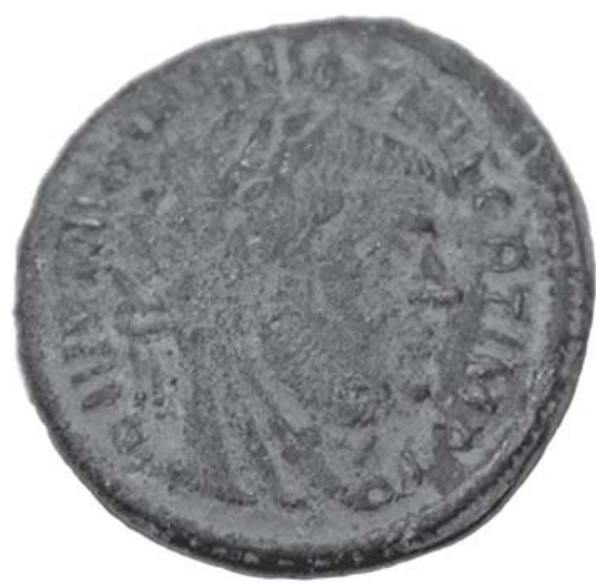

- Datação: Roma, 317-318. AE / Follis

- Anverso: Imperador velado e laureado à direita - Legenda: DIVO MAXIMIANO SEN FORT IMP

Desenvolvimento: Divo Maximiano Sen(iori)

Fort(issimo)Imp(eratori)

Tradução: Ao divino Maximiano Sênior Impera dor Fortíssimo

- Reverso: Leão avançando para a direita, com sua cauda suspensa

- Exergo: R[P]

- Legenda: MEMORIAE AETERNAE

Tradução: Memórias eternas

- Raridade: entre $\mathrm{r}^{2}$ e $\mathrm{r}^{3}$ (depende da oficina)

- Bibliografia: RIC VII, Roma 123

- Escala: 9:1 


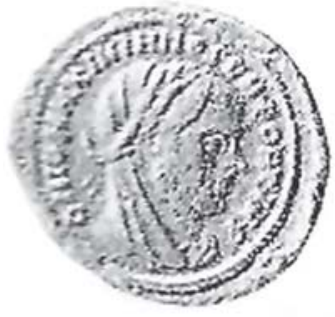

110

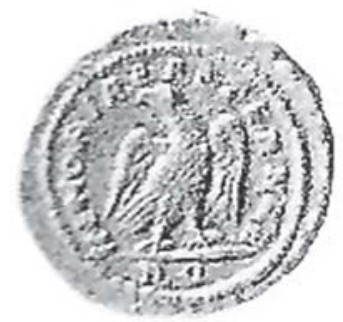

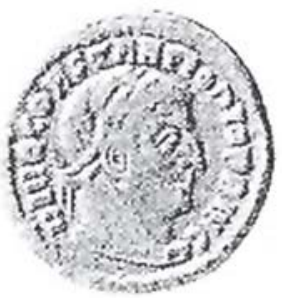

114

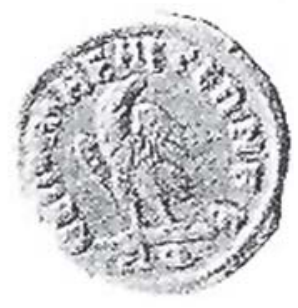

- Datação: Roma, 317-318. AE / Follis

- Anverso: Imperador velado e laureado à direita - Legenda: DIVO MAXIMIANO SEN FORT IMP

Desenvolvimento: Divo Maximiano Sen(iori) Fort(issimo)Imp(eratori)

Tradução: Ao divino Maximiano Sênior Im perador Fortíssimo

- Reverso: águia com as asas estendidas, voltada para a esquerda, e com a cabeça voltada para a direita

- Exergo: R[P]

Legenda: MEMORIAE AETERNAE

Tradução: Memórias eternas

- Raridade: entre $\mathrm{r}^{2}$ e $\mathrm{r}^{3}$ (depende da oficina)

- Bibliografia: RIC VII, Roma 110

- Escala: 6:1

Este tipo de moeda foi cunhado apenas em

Roma, deste modo, estamos perante a uma série comemorativa especial que exibe características diferentes das moedas anteriormente analisadas. Inicialmente, a legenda MEMORIAE AETERNAE é uma legenda em nominativo que denota a permanência da memória dos imperadores, isto é, de seus grandes feitos para o bem da Res publica.

Em segundo lugar, temos nos reversos a representação de dois animais profundamente ligados ao poder político e militar. O leão cumpria uma função central nas representações do poder no Oriente Próximo - como podemos observar nos relevos mesopotâmicos, nas metáforas bíblicas e outros -; neste caso, também percebemos as vinculações entre esta imagem e o poder imperial.

Quanto à águia, ela é o atributo de Zeus/ Júpiter, e personificação do poder imperial.
Além disso, a águia cumpria um papel central na cerimônia da consecratio pela qual o imperador falecido se tornava um diuus. Segundo Simon Price (1987: 61) - quando estudou a consecratio dos imperadores romanos - a águia era responsável por transportar a alma dos imperadores para o céu, daí sua importância nos relevos funerários, e a soltura de uma águia após o ritual de cremação.

Outra característica desta cunhagem de Roma são as titulaturas simples, com as legendas DIVO CLAUDIO, DIVO CONSTANTIO e DIVO MAXIMIANO SEN. Nos dois primeiros casos esta fórmula onomástica se encontra apenas nas moedas que apresentam a imagem da águia no reverso.

No caso de Maximiano, este aparece com o epíteto SENIOR para diferenciá-lo de Maximiano Galério (293-311) - seu genro - que também se apresentava apenas como Maximiano em suas moedas.

Por conseguinte, as emissões tinham o claro objetivo de honrar as memórias de Cláudio Gótico, Constâncio e Maximiano e, por conseguinte, glorificar seus descendentes, e afirmar a legitimidade da sucessão até Constantino e seus filhos.

\section{O papel dos diui na afirmação política}

Após o exame de nosso corpus numismático, apreendemos as características das representações dos diui nos territórios de Constantino. Agora passaremos à análise do "por quê" de este imperador ter cunhado estas moedas, entre os anos 317 e 318 .

Estas séries sucederam ao primeiro conflito entre Constantino e Licínio após o encontro de Milão em 313. Neste encontro foi firmada a aliança entre ambos os imperadores, com o casamento de Licínio com Constância - irmã de Constantino -, e a afirmação de Constantino e Licínio como imperadores legítimos do Ocidente e do Oriente, respectivamente.

Após este encontro, Constantino seguiu para a Gália para defendê-la das incursões germanas, e Licínio seguiu para o Oriente onde derrotou Maximino Daia, em fins de 313. Entretanto, uma disputa em torno da nomeação 
de Bassiano como César, em 315, levou ao conflito aberto entre os antigos aliados (Origo 14-15).

Após a comemoração de sua decennalia em Roma - em 315 -, Constantino marchou em direção aos territórios de Licínio, avançando sobre a província da Panônia, e tomando sua capital, a cidade de Siscia. Em seguida avançou até a província da Trácia - tomando a cidade de Tessalônica um importante centro de cunhagem balcânico -, obrigando Licínio a negociar uma paz desfavorável.

Pelos termos, Constantino se apoderou da região central da península balcânica, ganhando uma saída para o mar Egeu, além disso, conseguiu a nomeação de seus dois filhos - Crispo e Constantino II - como Césares, juntamente com seu sobrinho - e filho de Licínio - Licínio II, os quais foram proclamados em 317 .

A aclamação destes Césares tornou patente que o instável modelo tetrárquico de gestão colegiada foi repelido em favor de um modelo dinástico mais estável, uma vez que se tinha entre os cinco governantes quatro descendentes diretos de Constâncio.

Além disso, deste mesmo ano data a reabilitação da memória de Maximiano Hercúleo avô de Constantino II - cuja damnatio memoriae havia sido ordenada, nos territórios de Constantino, no ano de 311 - e que foi estendida a todo o Império Romano após 313. Este foi o único caso de que temos vestígios documentais de uma reabilitação de memória na história do Império Romano, e que só pode ser entendida tendo em vista o contexto de afirmação de uma sucessão dinástica.

Relaciona-se a reiteração do papel de Cláudio Gótico como ancestral de Constâncio Cloro, e por sua vez, afirma-se a existência de uma sucessão dinástica de 50 anos, entrecortada por 23 anos (270-293) nos quais não havia um descendente de Cláudio no poder.

Neste sentido, as emissões monetárias de 317-318 tinham por objetivo afirmar a existência de uma herança dinástica da família de Constantino sobre a de Licínio. Estas séries de moedas de bronze, emitidas pelos principais centros de cunhagem de seus domínios ocidentais (Trier, Arles, Roma e Aquiléia) e de seus novos domínios nas regiões orientais (Siscia e Tessalônica), celebravam uma memória dinástica.
Estas moedas honravam os divinos Cláudio Gótico, Constâncio Cloro e Maximiano Hercúleo e faziam lembrar aos antigos e novos súditos de Constantino de quais imperadores descendia sua família - dos grandes imperadores ilíricos que através de seus méritos militares iniciaram uma época de restauração da ordem no Império Romano.

As moedas de bronze tinham uma grande dispersão, principalmente por serem utilizadas nos pagamentos dos soldos, e nas pequenas transações cotidianas - uma vez que a cunhagem de prata tornou-se rara após a crise de do século III. Assim sendo, afirmava-se a relação entre memória e legitimidade, posto que os grupos sociais que tinham contato com estas moedas também conheciam os feitos desses imperadores.

Neste caso, o uso da memória cumpria o papel de afirmação dinástica de Constantino sobre Licínio com o intuito de esvaziar a legitimidade deste. Interessante notarmos, através das emissões monetárias, que Licínio se refugiou nas imagens de Júpiter, associando-se a este deus, enquanto Constantino cessa de cunhar moedas com esta imagem (as últimas datam de 321-2, pouco antes do início do decisivo conflito contra Licínio), e passou a exaltar outros temas que não os deuses do panteão tradicional.

A descendência divina demonstrava que o imperador era de uma natureza superior ao conjunto dos súditos, sendo um centro irradiador de sacralidade, e o ponto focal de uma identidade romana baixo-imperial. Neste sentido, havia a necessidade da difusão de todo este repertório simbólico que relacionava o imperador com o plano divino, sendo a utilização da memória de seus antepassados divinizados uma ponte entre os planos terreno e celeste.

Por fim, embora esta cunhagem tenha sido apenas emitida entre 317 e 318, e por seis Casas de Cunhagem, percebemos um papel importantíssimo da moeda como veículo de divulgação dos discursos de poder de Constantino. Por conseguinte, observamos a utilização da memória histórica destes imperadores divinizados como um instrumento e objeto de poder, uma vez que afirmava o princípio dinástico, e, deste modo, provia de legitimidade o poder imperial de Constantino I e seus descendentes frente a Licínio, e quaisquer outros pretendentes. 
SILVA, D.P. Memory and Legitimation: the monetary typologies of Claudius Gothicus, Constantius Clorus and Maximianus Herculius (317-318). Revista do Museu de Arqueologia e Etnologia, São Paulo, 18: 279-286, 2008.

Abstract: In this article, we aim to investigate the uses of memory in Constantine's (306-337) political legitimation, through the analysis of typologies and monetary legends of diui Claudius Gothicus (268-270), Constantius Clorus (293-306) and Maximianus Herculius (286-305, 306-308), issued by the mint houses of Aquileia, Arles, Rome, Siscia, Thessalonica and Trier between the years of 317 and 318 .

Keywords: Later Roman Empire - Constantine I - Memory - Legitimation Numismatics.

\section{Bibliografia}

\section{Documentação escrita}

[Anonymus Valesianus]

1939 Excerpta Valesiana; Pars Prior: Origo Constantini Imperatoris. (The Loeb Classical Library) Harvard: Harvard University Press.

\section{RODGERS, B.S.}

1995 In Praise of Later Roman Emperors: The Panegyric Latini. Tr. Nixon, C.E.V. Berkeley: University of California Press.

\section{SCRIPTORES HISTORIAE AUGUSTAE}

1953 Tr. Magie, D. (The Loeb Classical Library) London: William Heinemann.

\section{Referências bibliográficas}

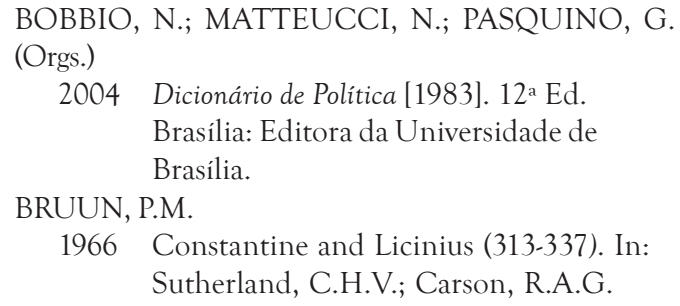
Sutherland, C.H.V.; Carson, R.A.G.

(Eds.) The Roman Imperial Coinage. v. VII. London, Spink and Son Ltd.

CATROGA, F.

2001 Memória, História e Historiografia. Coimbra: Editora Quarteto.

FARIA, E.

1967 Dicionário Latino-Português. Rio de Janeiro: MEC.

FLORENZANO, M.B.B.

1985 Iconografia monetária: funções e interpretações. (Texto de conferência proferida no Museu Histórico Nacional - Rio de Janeiro, quando do II Simpósio Nacional de História Antiga e Medieval).

HOWGEGO, CH.

1995 Ancient History from coins. New York: Routledge.

NORA, P.

1984 Les lieux de memóire. I La République. Paris: Editions Gallimard.

PRICE, S.

1987 From noble funerals to divine cult: the consecration of Roman Emperors. In: Cannadine, D.; Price, S. (Eds.) Rituals of Royalty. Cambridge, Cambridge University Press: 56-105. 